\title{
Commentary: CSF and Plasma Testosterone in Attempted Suicide
}

\author{
Leo Sher ${ }^{\star t}$ \\ James J. Peters Veterans' Administration Medical Center and Icahn School of Medicine at Mount Sinai, New York, NY, USA
}

Keywords: testosterone, CSF, mood, behavior, attempted suicide

\section{A commentary on}

CSF and Plasma Testosterone in Attempted Suicide

by Stefansson J, Chatzittofis A, Nordström P, Arver S, Åsberg M, Jokinen J. Psychoneuroendocrinology

(2016) 74:1-6. doi: 10.1016/j.psyneuen.2016.08.009

OPEN ACCESS

Edited by:

Frederick Robert Carrick,

Bedfordshire Centre for Mental

Health Research in Association with

University of Cambridge, UK

Reviewed by:

Ahmed Eid Elaghoury,

Ministry of Health and Population,

Egypt

Ahmed Hankir,

Bedfordshire Centre for Mental Health Research in Association with

University of Cambridge, UK

${ }^{*}$ Correspondence:

Leo Sher

drleosher@gmail.com

${ }^{+}$Leo Sher, M.D., is the Chair of the World Federation of Societies of Biological Psychiatry Task Force (WFSBP) on Men's Mental Health.

Specialty section: This article was submitted to Child Health and Human Development, a section of the journal Frontiers in Public Health

Received: 12 December 2016 Accepted: 06 April 2017

Published: 24 April 2017

Citation:

Sher L (2017) Commentary: CSF and Plasma Testosterone in Attempted Suicide.

Front. Public Health 5:92. doi: 10.3389/fpubh.2017.00092
The role of testosterone in the pathophysiology of suicidal behavior remains unclear. Therefore, a recent research report "CSF and plasma testosterone in attempted suicide" by Stefansson et al. published in Psychoneuroendocrinology is an important and timely contribution to the field (1). The authors examined the CSF and plasma testosterone and cortisol levels in medication-free suicide attempters and healthy volunteers. The authors also assessed the relationship between the testosterone/cortisol ratio, aggressiveness, and impulsivity in suicide attempters. This research group, led by Dr. Jussi Jokinen, found that male suicide attempters had higher CSF and plasma testosterone levels than age-matched male healthy volunteers. The researchers did not observe significant differences in CSF testosterone levels between female suicide attempters and healthy female volunteers. The authors observed that in male suicide attempters, the CSF testosterone/cortisol ratio showed a significant positive correlation with impulsivity and aggressiveness. This research work is important not only because it shows that testosterone may be involved in the pathophysiology of suicidal behavior but also because it suggests a potential psychobiological mechanism: it appears that impulsivity and aggressiveness may in fact mediate the effect of testosterone on suicidality. This is consistent with my hypothesis proposed in 2012 (2). I suggested that if testosterone plays a role in the neurobiology of suicidal behavior, this connection may be related to (1) a direct effect of testosterone on suicidality; (2) a testosterone effect on mood and, consequently, suicidality; (3) a testosterone effect on cognition and, consequently, suicidality; and (4) a testosterone effect on aggression and, consequently, suicidality.

Testosterone is a steroid hormone from the androgen group $(3,4)$. In humans, testosterone is primarily secreted in the testicles of males and the ovaries of females. Testosterone is the principal male sex hormone. The best known neurobehavioral effects of testosterone are on sexual function and aggression $(5,6)$. However, there is evidence that testosterone and other androgens might be involved in the pathophysiology of mood disorders and suicidal behavior (7-15).

Most but not all investigations of the relationship between testosterone and suicidality found relations between testosterone and suicidal behavior. A systematic review and meta-analysis related to a link between testosterone and suicidality have never been conducted. At least six studies indicated that testosterone levels are associated with suicidal behavior. Roland et al. (9) examined postmortem serum testosterone levels in males who died by suicide and sudden death male victims. They found that among 23- to 45-year-old males testosterone levels were significantly higher in the suicide group compared to the sudden death group. Tripodianakis et al. (10) observed significantly lower testosterone levels in male suicide attempters compared to controls. Markianos et al. (11) compared levels of plasma testosterone in psychiatric patients who had attempted suicide by jumping, male subjects who were hospitalized after accidentally falling from a high height, and healthy controls. 
Compared with a healthy control group, both accident and attempt groups had lower testosterone levels. There was a trend toward lower testosterone levels in suicide attempter group compared with levels in the accident group. We found that controlling for sex testosterone levels positively correlated with the number of manic episodes and the number of suicide attempts in bipolar suicide attempters (12). We also observed that in females with bipolar disorder with at least one past suicide attempt, higher baseline testosterone levels predicted suicide attempts during the follow-up period (13). Zhang et al. (14) compared testosterone levels in a large sample of suicide attempters and a large sample of healthy controls. Male or female suicide attempters had higher testosterone levels compared to male or female controls, respectively.

However, at least two studies did not support that there is a relation between testosterone and suicide. Butterfield et al. (16) did not find a difference in testosterone levels between male veteran suicide attempters with posttraumatic stress disorder (PTSD) and male veteran non-attempters with PTSD. Perez-Rodriguez et al. (17) did not find a difference in blood testosterone levels in male suicide attempters and healthy male subjects. It looks like the balance of evidence is in favor of the view that testosterone is involved in the pathophysiology of suicidality. We should, however, remember that many negative studies are not published.

It is important to note that most of the studies of the relationship between testosterone and suicidality including the study by Stefansson et al. (1) are cross sectional, i.e., the findings cannot speak to causation. Case-control studies are retrospective by their very nature: the case patients are selected because they

\section{REFERENCES}

1. Stefansson J, Chatzittofis A, Nordström P, Arver S, Åsberg M, Jokinen J. CSF and plasma testosterone in attempted suicide. Psychoneuroendocrinology (2016) 74:1-6. doi:10.1016/j.psyneuen.2016.08.009

2. Sher L. Testosterone and suicidal behavior. Expert Rev Neurother (2012) 12(3):257-9. doi:10.1586/ern.12.6

3. Shahidi NT. A review of the chemistry, biological action, and clinical applications of anabolic-androgenic steroids. Clin Ther (2001) 23(9):1355-90. doi:10.1016/S0149-2918(01)80114-4

4. Brinkmann AO. Molecular mechanisms of androgen action - a historical perspective. Methods Mol Biol (2011) 776:3-24. doi:10.1007/978-1-61779-243-4_1

5. Rosell DR, Siever LJ. The neurobiology of aggression and violence. CNS Spectr (2015) 20(3):254-79. doi:10.1017/S109285291500019X

6. Gray PB, McHale TS, Carré JM. A review of human male field studies of hormones and behavioral reproductive effort. Horm Behav (2016). doi:10.1016/j. yhbeh.2016.07.004

7. Ebinger M, Sievers C, Ivan D, Schneider HJ, Stalla GK. Is there a neuroendocrinological rationale for testosterone as a therapeutic option in depression? J Psychopharmacol (2009) 23(7):841-53. doi:10.1177/0269881108092337

8. Zarrouf FA, Artz S, Griffith J, Sirbu C, Kommor M. Testosterone and depression: systematic review and meta-analysis. J Psychiatr Pract (2009) 15(4):289-305. doi:10.1097/01.pra.0000358315.88931.fc

9. Roland BC, Morris JL, Zelhart PF. Proposed relation of testosterone levels to male suicides and sudden deaths. Psychol Rep (1986) 59:100-2. doi:10.2466/ pr0.1986.59.1.100

10. Tripodianakis J, Markianos M, Rouvali O, Istikoglou C. Gonadal axis hormones in psychiatric male patients after a suicide attempt. Eur Arch Psychiatry Clin Neurosci (2007) 257:135-9. doi:10.1007/s00406-006-0686-y

11. Markianos M, Tripodianakis J, Istikoglou C, Rouvali O, Christopoulos M, Papageorgopoulos P, et al. Suicide attempt by jumping: a study of gonadal have developed the outcome of interest, e.g., suicide attempt (18). At the same time, case-control studies are very good for the investigation of risk factors when the outcome of interest is rare, such as suicide, as it would be difficult or impossible to recruit a prospective cohort.

To a certain extent, suicidality is a proxy of the severity of psychiatric illness. Therefore, it is somewhat difficult to attribute high testosterone levels to suicidal behavior but not to those psychiatric disorders that are closely linked to suicidality.

Even in the literature on the better established link between testosterone and aggressive behavior, there are research reports that have generated mixed findings (19-22). For example, some studies suggested that higher testosterone levels are linked to aggression in men (19-21). However, a 2014 article reported that there was a significant positive correlation between testosterone levels and violent behaviors among females, but not males (22).

It is interesting to speculate that testosterone may mediate the effect of sunshine on suicidal behavior. Seasonal variations of testosterone levels and a possible impact of sunshine on suicidality have been described in the literature (23-25).

The role of testosterone and other hormones in the neurobiology of suicide remains poorly studied and poorly understood. This is a difficult field for research, but the time is ripe for active scientific research on the psychoneuroendocrinology of suicide.

\section{AUTHOR CONTRIBUTIONS}

The author confirms being the sole contributor of this work and approved it for publication. axis hormones in male suicide attempters versus men who fell by accident. Psychiatry Res (2009) 170:82-5. doi:10.1016/j.psychres.2008.08.001

12. Sher L, Grunebaum MF, Sullivan GM, Burke AK, Cooper TB, Mann JJ, et al. Testosterone levels in suicide attempters with bipolar disorder. J Psychiatr Res (2012) 46:1267-71. doi:10.1016/j.jpsychires.2012.06.016

13. Sher L, Grunebaum MF, Sullivan GM, Burke AK, Cooper TB, Mann JJ, et al. Association of testosterone levels and future suicide attempts in females with bipolar disorder. J Affect Disord (2014) 166:98-102. doi:10.1016/j.jad. 2014.04.068

14. Zhang J, Jia CX, Wang LL. Testosterone differs between suicide attempters and community controls in men and women of China. Physiol Behav (2015) 141:40-5. doi:10.1016/j.physbeh.2015.01.004

15. Kiraly DD, Sher L. Low testosterone in a young combat veteran with dual diagnosis and suicidal behavior: a case study. Int J Adolesc Med Health (2015) 27(2):235-7. doi:10.1515/ijamh-2015-5018

16. Butterfield MI, Stechuchak KM, Connor KM, Davidson JR, Wang C, MacKuen $\mathrm{CL}$, et al. Neuroactive steroids and suicidality in posttraumatic stress disorder. Am J Psychiatry (2005) 162:380-2. doi:10.1176/appi.ajp.162.2.380

17. Perez-Rodriguez MM, Lopez-Castroman J, Martinez-Vigo M, Diaz-Sastre C, Ceverino A, Núñez-Beltrán A, et al. Lack of association between testosterone and suicide attempts. Neuropsychobiology (2011) 63:125-30. doi:10.1159/ 000318085

18. Young JM, Solomon MJ. How to critically appraise an article. Nat Clin Pract Gastroenterol Hepatol (2009) 6(2):82-91. doi:10.1038/ncpgasthep1331

19. Ehrenkranz J, Bliss E, Sheard MH. Plasma testosterone: correlation with aggressive behavior and social dominance in man. Psychosom Med (1974) 36(6):469-75. doi:10.1097/00006842-197411000-00002

20. Giammanco M, Tabacchi G, Giammanco S, Di Majo D, La Guardia M. Testosterone and aggressiveness. Med Sci Monit (2005) 11(4):RA136-45.

21. Archer J. The influence of testosterone on human aggression. Br J Psychol (1991) 82(Pt 1):1-28. doi:10.1111/j.2044-8295.1991.tb02379.x 
22. Assari S, Caldwell CH, Zimmerman MA. Sex differences in the association between testosterone and violent behaviors. Trauma Mon (2014) 19(3):e18040. doi:10.5812/traumamon.18040

23. Vyssoki B, Kapusta ND, Praschak-Rieder N, Dorffner G, Willeit M. Direct effect of sunshine on suicide. JAMA Psychiatry (2014) 71(11):1231-7. doi:10.1001/ jamapsychiatry.2014.1198

24. Svartberg J, Jorde R, Sundsfjord J, Bønaa KH, Barrett-Connor E. Seasonal variation of testosterone and waist to hip ratio in men: the Tromsø study. J Clin Endocrinol Metab (2003) 88(7):3099-104. doi:10.1210/jc.2002-021878

25. Andersson AM, Carlsen E, Petersen JH, Skakkebaek NE. Variation in levels of serum inhibin $\mathrm{B}$, testosterone, estradiol, luteinizing hormone, folliclestimulating hormone, and sex hormone-binding globulin in monthly samples from healthy men during a 17-month period: possible effects of seasons. J Clin Endocrinol Metab (2003) 88(2):932-7. doi:10.1210/jc.2002-020838
Conflict of Interest Statement: The author declares that the research was conducted in the absence of any commercial or financial relationships that could be construed as a potential conflict of interest.

The reviewer, $\mathrm{AH}$, and handling editor declared their shared affiliation, and the handling editor states that the process nevertheless met the standards of a fair and objective review.

Copyright (C) 2017 Sher. This is an open-access article distributed under the terms of the Creative Commons Attribution License (CC BY). The use, distribution or reproduction in other forums is permitted, provided the original author(s) or licensor are credited and that the original publication in this journal is cited, in accordance with accepted academic practice. No use, distribution or reproduction is permitted which does not comply with these terms. 